\title{
Analysis of The Time Value for Public Transport Passenger by Using Random Regret Minimization
}

\author{
Medis Surbakti ${ }^{l}$ and Fransiscus Pinem ${ }^{l}$ \\ ${ }^{1}$ Department of Civil Engineering, University of Sumatera Utara, Indonesia
}

\begin{abstract}
This study aims to analyze the value of time a public transport passengers in Medan which is the amount of money issued by a person who was willing to save one unit of time traveling. An investment in transport projects should consider the high or low travel speeds for road users, whenever he or she is the driver, passengers or goods that were transported. Savings or reduction in the value of time is one of the advantages in transportation projects. Random Regret Minimization is a new method that can be used to calculate the value of time. The value of the travel time of passenger public transportation Medan with Random Regret Minimization method is Rp.6687.52/hour/person. Regret Minimization showed significantly different results with the Mode Choice Approach method and the Income Approach. This shows the tendency of public transport passengers in Medan to avoid the regret that will arise when the monorail will operate later.
\end{abstract}

\section{Introduction}

Transport Is an attempt to move people, animals or goods from one place to another by using a vehicle driven by human or machine. Along with the economic growth of a region, the demand for transportation will be even greater. So in general, the increase in the economic is reflected in the raise in the number and quality of mode of transportation. Medan is one of the largest cities in Indonesia, which has a lot of transportation problems that are quite complicated. To solve the problem, the city government in collaboration with the private sector (Public Private Partnership) is planning the construction and development of the monorail transportation modes.

Planning and construction of the Monorail Medan are still in the early stages of the study, but it is important to estimate the impact of the emergence of new modes of transport. In addition to the calculation of the negative impact, positive impact on the operation of the monorail also is analyzed. The value of travel time is a form of analysis that is needed in knowing the economic feasibility of a new mode of transportation. Passenger travel time value of different types of public transport modes that operate in the city of Medan will be one of the references of the time value.

The purpose of this study is to determine the value of public transport users in Medan, as a component for the calculation of the feasibility of operation modes of transport monorail, as a new mode of transportation in the city of Medan.

Transport is an attempt to move people, animals or goods from one place to another by using a vehicle driven by human or machine. Along with the economic growth of a region, the demand for transportation will be even greater. So in general, the increase in the 
economic is reflected in the raise in the number and quality of mode of transportation. Medan is one of the largest cities in Indonesia, which has a lot of transportation problems that are quite complicated. To solve the problem, the city government in collaboration with the private sector (Public Private Partnership) is planning the construction and development of the monorail transportation modes.

Planning and construction of the Monorail Medan is still in the early stages of the study, but it is important to estimate the impact of the emergence of new modes of transport. In addition to the calculation of the negative impact, positive impact on the operation of the monorail also is analyzed. The value of travel time is a form of analysis that is needed in knowing the economic feasibility of a new mode of transportation. Passenger travel time value of different types of public transport modes that operate in the city of Medan will be one of the references of the time value.

The purpose of this study is to determine the value of public transport users in Medan, as a component for the calculation of the feasibility of operation modes of transport monorail, as a new mode of transportation in the city of Medan.

\section{Literature Review}

Time Value is the amount of money a person will pay to save one unit of travel time [5]. As is well known, investment in a transport project should take into account the high speeds of road users traveling. Therefore, the procurement of transport facilities should provide an opportunity for road users to save travel time so that the time saved can be used to perform other activities.

The existence of the monorail will be expected to facilitate the high mobility of the people who will use the monorail. In addition to being a mass public transport, the monorail is expected to serve the needs of passengers better than existing public transportation in terms of comfort and timeliness. The monorail is a metro vehicle that has its track, so its movement is not influenced by other vehicles. This causes the monorail to move more quickly and on time. With the efficiency of time and reliability of this monorail, it is expected to be worth the rate to be applied. Therefore it is important to know the value of travel time from passengers who have the potential to ride this monorail.

Some factors that affect travel time value [5]:

1. Income Level

2. Travel Length

3. Travel Mode

4. Time Period

5. The Purpose of Travel

6. Environmental Conditions

Estimating the value of travel time is to try to place the value of money on the travel time savings due to the emergence of a new transport facility. There are several methods to calculate travel time value. Among them is to use the preferred approach between the existing mode and the new mode to be implemented and the second is the income level approach.

\subsection{Random Regret Minimization}

There are two theories that explain the preferred approach between the existing mode and the mode that will operate, the regret minimizing theory and the theory of utility 
maximization. In 2008, Chorus explained Regret's minimizing theory (RRM) that in choosing a choice, one would further minimize regrets that would arise rather than maximize the value of the utility [3]. The method of Random Regret Minimization is based on the intuition of an individual's behavior that has been based on the paradigm of choosing utility improvement (in this case the individual psychological approach is more prominent)[4].

Similar to the utility maximization method, the time value can also be calculated by the Random Regret Minimization method. The time value with the Random Regret Minimization Method can be calculated by the following formula:

Where:

$$
\text { Value Of Time RRM }=\frac{\sum_{i \neq j}\left(\frac{-\beta_{T T}}{1+\frac{1}{\exp \left[\beta_{T T}(T T j-T T i)\right]}}\right)}{\sum_{i \neq j}\left(\frac{-\beta T C}{1+\frac{1}{\exp \left[\beta_{T c}(T C j-T C i)\right]}}\right)}
$$

TT $=$ Travel Time (minute)

$\mathrm{TC}=$ Travel Cost (rupiah)

$\beta_{T T}=$ Travel Time Attribute coefficient

$\beta_{T C}=$ Travel Cost Attribute coefficient

$i, j=$ alternative Mode (moda $i, j$ )

\subsection{Mode Choice Approach/Maximum Utility Approach}

This method attempts to determine the time value of the model, to estimate the choice ratio of a mode of transport. In this method, the comparison of options is assumed to be a function of two variables: operating cost and time cost. The time value is defined as the ratio between the travel time coefficient and the travel cost coefficient.

$$
P i=a_{0}+a_{1}(C i-C j)+a_{2}(T i-T j)
$$

Where:

$\mathrm{Pi}=$ Ratio to choose mode $\mathrm{i}$

$\mathrm{C}, \mathrm{T}=\operatorname{Cost}(\mathrm{C})$ and Time $(\mathrm{T})$

$\mathrm{i}, \mathrm{j}=$ mode Alternative

$a_{0}, a_{1}, a_{2}, \ldots=$ Coefficient

The value of travel time obtained from the method is the comparison between the coefficient of travel time and travel cost coefficient.

$$
\text { Value of Time }=\frac{B_{-} T I M E}{B_{-} \operatorname{COST} *}=\frac{\beta_{T T}}{\beta_{T C}}
$$

\subsection{Income Approach}

The time value is usually proportional to per capita income and is a fixed ratio to the income level. But this is a rather bold assumption because there is little or no empirical data to support it [5]. Time value calculation taking into account per capita income (GRDP) can be formulated as follows:

$$
\text { Value of Time }=\frac{P D R B / J P}{W K T}
$$


Where :

PDRB $=$ Gross Regional Domestic Revenue (per capita/Rp)

$\mathrm{JP} \quad=$ Number of population (orang)

WKT $=$ Total Work Time, Annual (hour)

\section{Method}

The stages of research activity in this study as follows:

1. Identify the travel characteristic of modes that will be operating. In this type of mode of transportation that will be the object of research is a monorail service that will be substitute another type of public transport even private transport.

2. Designing survey forms. To design the survey form, the technique used is the stated preference. By using this technique, the question can be posed to the respondents are changes in both the increase or decrease in the value of similar attributes in both modes and relevance to the modal choice preferences.

3. The data collection process. Survey forms that have been designed and is disseminated to users of the public transport and private transport which makes a start or end their travel from monorail service area corridor. Figure 1 bellow describes the plan of monorail route in Medan.

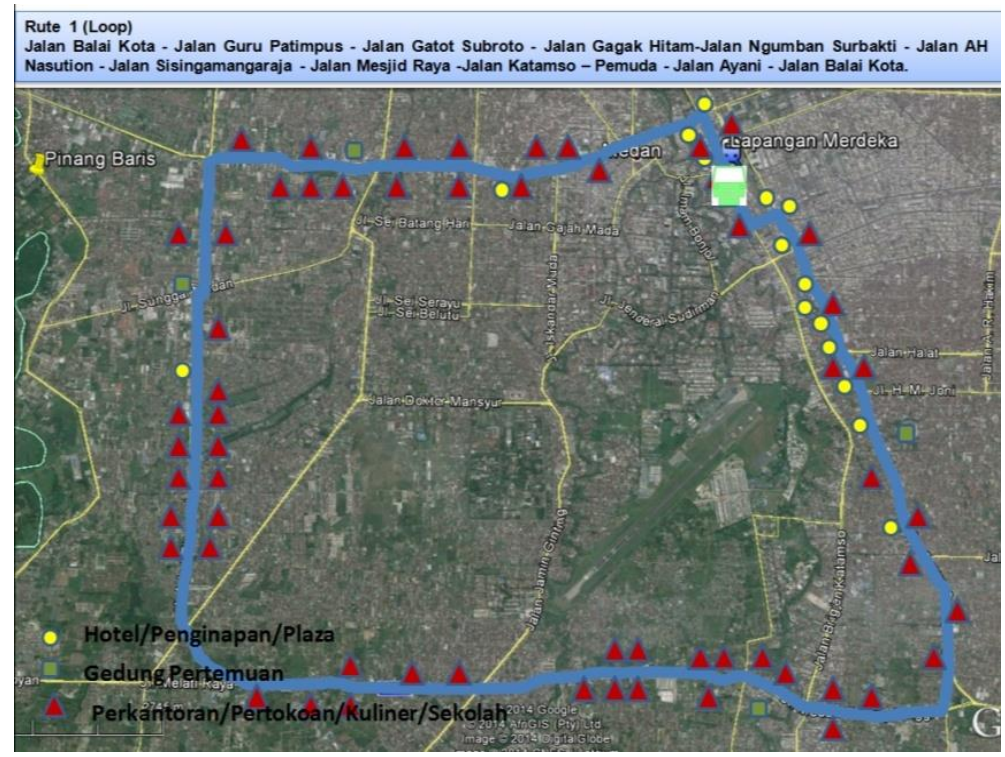

Medan City
Figure 1. Route Plan to be passed by the monorail of

4. Mode Choice Modelling. The data have been collected and processed to obtain a modal choice models. The next step is a test of the model, to determine their validity

5. Analysis the Model. Models are declared valid by statistical analysis, and then analyzed the coefficient of travel time and travel cost, for random regret modelling and modeling choice approach (maximum utility approach). 


\section{Result and Discussion}

To analyze the parameters needed to calculate the time value, in this study used Biogeme 2.2 software. (BIerlaire Optimization toolbox for GEv Model Estimation) [1]. For Random Regrete Minimization, output from Biogeme can be seen bellow:

Table 1. Parameters from Biogeme software result.

\begin{tabular}{|c|c|c|}
\hline NO & PARAMETER & VALUE \\
\hline 1 & Number of observations & 1417 \\
\hline 2 & Number of individuals & 1417 \\
\hline 3 & Null log-likelihood & -982.19 \\
\hline 4 & Cte log-likelihood & -965.19 \\
\hline 5 & Init log-likelihood & -982.19 \\
\hline 6 & Final log-likelihood & -678.04 \\
\hline 7 & Likelihood ratio test & 608.299 \\
\hline 8 & Rho-square & 0.31 \\
\hline 9 & Adjusted rho-square & 0.306 \\
\hline 10 & B_TIME & -0.218 \\
\hline 11 & B_COST & -0.343 \\
\hline 12 & B_WT & -0.203 \\
\hline
\end{tabular}

Table 2. Value of Time with RRM approach

\begin{tabular}{|c|c|c|}
\hline NO & PARAMETER & VALUE \\
\hline 1 & B_TIME & -0.218 \\
\hline 2 & B_COST & -0.343 \\
\hline \multicolumn{2}{|c|}{$\sum_{i \neq j}\left(\frac{-\beta_{T T}}{\left.1+\frac{1}{\exp \left[\beta_{T T}(T T j-T T i)\right]}\right)}\right)$} & 286.72 \\
\hline \multicolumn{2}{|c|}{$\sum_{i \neq j}\left(\frac{-\beta T C}{\left.1+\frac{1}{\exp \left[\beta_{T c}(T C j-T C i)\right]}\right)}\right)$} & 257.25 \\
\hline Value Of Time & $\mathrm{Rp} \mathrm{6.687}$ \\
\hline
\end{tabular}

For maximization utility using discrete choice model can be seen bellow;

Table 3. Value of Time with Maximum Utility approach

\begin{tabular}{|c|c|c|}
\hline NO & PARAMETER & VALUE \\
\hline 1 & B_TIME & -0.218 \\
\hline 2 & B_COST & -0.343 \\
\hline & Value of Time (Rupiah/jam) & $\mathrm{Rp} \mathrm{3.813}$ \\
\hline
\end{tabular}

For the value of Time based on the Income approach, can be seen in Table 4.

Table 4. Value of Time based on Income approach

\begin{tabular}{|l|l|}
\hline GRDP based on market price [2] & $\mathrm{Rp} \mathrm{138.020.000.000.000}$ \\
\hline GRDP based on fixed price & $\mathrm{Rp} \mathrm{108.222.000.000.000}$ \\
\hline
\end{tabular}




\begin{tabular}{|l|c|} 
Number of population & 13.326 .307 \\
\hline Income per capita & $\mathrm{Rp} 8.120 .897,26$ \\
\hline Work Hours/week & 40 \\
\hline Work hours annually & 2080 \\
\hline Value Of Time & $\mathrm{Rp} \mathrm{3.904}$ \\
\hline
\end{tabular}

From Table 1 to 4 above it can be concluded that there are differences in the results of the calculations of the three approaches, RRM has the greatest value of time compared to the other two approaches. This shows that "regret approach" will give the greatest preference value to "value of time" compared to an assessment based on "maximizing utility."

Value of time for different type of occupation can be shown bellow;

Table 5. Value of Time based on occupation

\begin{tabular}{|c|c|c|}
\hline Occupation & Approach & VOT \\
\hline \multirow{2}{*}{$\begin{array}{c}\text { Gov. Employees } \\
\text { Private } \\
\text { Employee }\end{array}$} & VOT/HOUR (BASED ON RRM) & 7809,4588 \\
\cline { 2 - 3 } & VOT/HOUR (Maximum Utility APPROACH) & 4441,55844 \\
\cline { 2 - 3 } Entrepreneur & VOT/HOUR (Maximum Utility APPROACH) & 3412,04819 \\
\cline { 2 - 3 } & VOT/HOUR (BASED ON RRM) & 11334,4739 \\
\hline \multirow{2}{*}{ Students } & VOT/HOUR (BASED ON RRM) & 6428,57143 \\
\cline { 2 - 3 } & VOT/HOUR (Maximum Utility APPROACH) & 990,723562 \\
\hline \multirow{2}{*}{ Others } & VOT/HOUR (BASED ON RRM) & 8750,31801 \\
\cline { 2 - 3 } & VOT/HOUR (Maximum Utility APPROACH) & 4923,07692 \\
\hline
\end{tabular}

From Table 5 above it is shown that for each type of work, the RRM approach will provide a higher VOT value than the maximum utility approach. The biggest VOT is the Private Employee, while the smallest is the student.

\section{References}

1. M. Bierlaire. Estimation of discrete choice models with Biogeme 1.8. Ecole Polytechnique Federale De Lausane. Transport and Mobility Laboratory. Switzerland. (2009)

2. Central Bureau of Statistics of North Sumatra. Area, Number of Population, and Population Density by Regency. [accesed 15 Agustus 2015] http://sumut.bps.go.id/frontend/linkTabelStatis/view/id/138. (2015)

3. C. Chorus. Random Regret-based discrete choice modeling: A tutorial. Springer, Hieldelberg, Germany. (2012)

4. M. Surbakti, A. F.Sadullah. Comparative Analysis Using RUM and RRM in the Mode Choice Behavior. Proceeding, Malaysian Universities Transport Research Forum Conference. (2013)

5. O. Tamin. Transportation Modelling and Planning: problems example and applications. ITB, Bandung. (2008) 